\title{
Análisis de viabilidad y diseño para el abastecimiento de agua potable en la vereda Socotá del municipio de Apulo (Cundinamarca, Colombia)
}

Feasibility Analysis and Design of a Drinking Water Supply System in the Village of Socotá, Municipality of Apulo (Cundinamarca, Colombia)

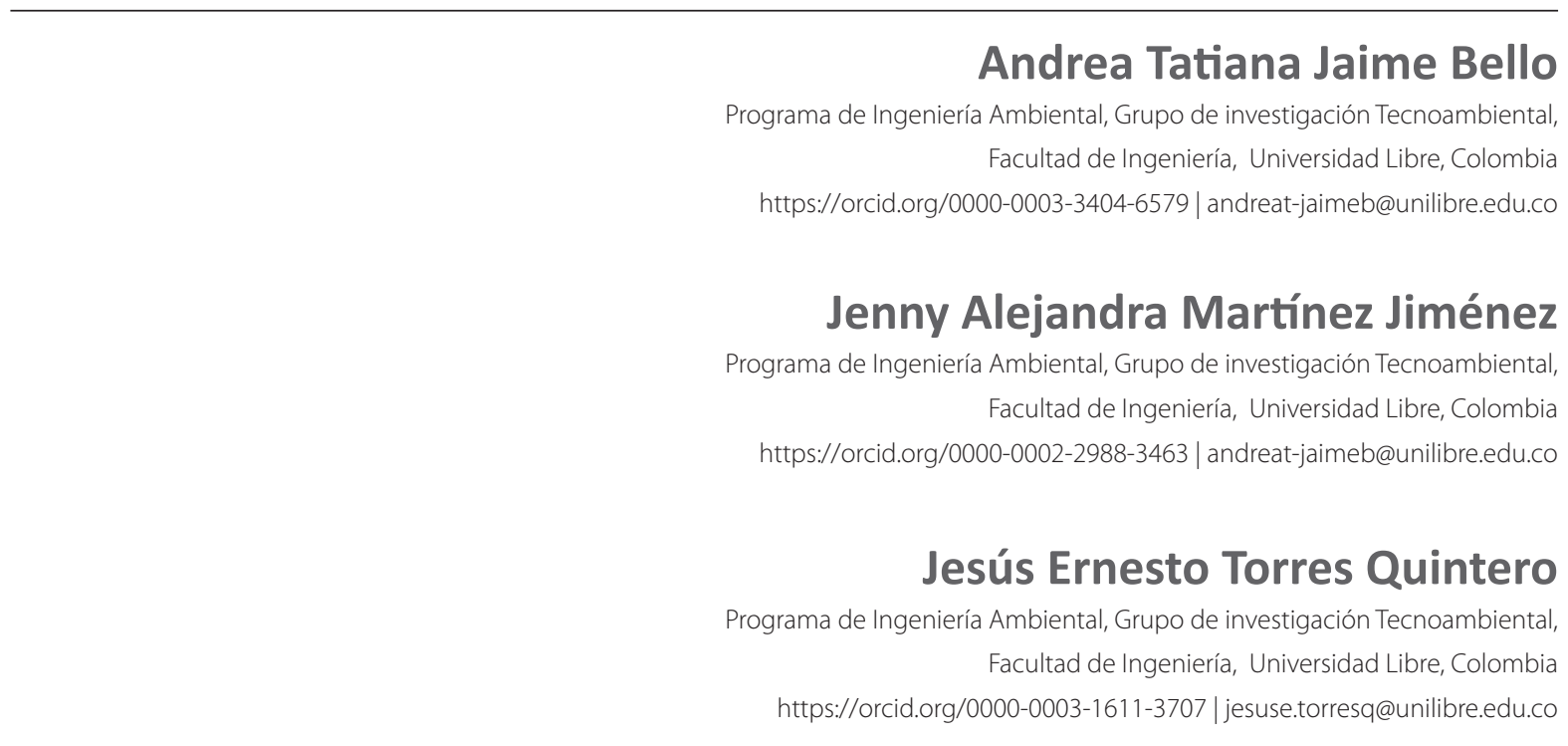

Fecha de recepción: 22 de abril de 2020 Fecha de aceptación: 30 de junio de 2020

Sugerencia de citación: Jaime-Bello, A. T., Martínez-Jiménez, J. A. y Torres-Quintero, J. E. (2020). Análisis de viabilidad y diseño para el abastecimiento de agua potable en la vereda Socotá del municipio de Apulo (Cundinamarca, Colombia). Mutis, 10(1), 79-96. doi: 10.21789/22561498.1604

\section{RESUMEN}

El deficiente desarrollo infraestructural en materia de agua potable y saneamiento básico en las zonas rurales de Colombia ha repercutido en la insatisfacción de las necesidades básicas de sus habitantes. Por lo anterior, esta investigación realiza la validación de los criterios fundamentales para el 
diseño de un sistema que permita abastecer de agua potable a la vereda Socotá, municipio de Apulo, aplicando metodologías como el método inverso a la distancia (IDW) para la determinación de la precipitación, el método de Thornthwaite para el cálculo de la evapotranspiración, el método geométrico para la proyección poblacional y la validación del cumplimiento de criterios para la selección de la opción de abastecimiento más viable, para su posterior diseño mediante las ecuaciones de Hazen-Williams. A partir de dichos métodos fue posible identificar una precipitación de 1.101-1.156 mm/año de carácter bimodal con períodos de bajo almacenamiento de agua y un caudal de $0,000295 \mathrm{~m}^{3} / \mathrm{s}$ para un total de 105 usuarios potenciales. Además, se estableció que la conexión al acueducto Asuarcopsa es la mejor alternativa de abastecimiento, para la cual se requiere un diámetro de tubería igual a una pulgada y un tanque de almacenamiento de $10.195 \mathrm{~L}$, siendo posible evidenciar a través de los resultados obtenidos las deficiencias de disponibilidad, continuidad y calidad de agua presentadas por el sistema de abastecimiento actual.

Palabras clave: agua potable, abastecimiento rural, disponibilidad, continuidad, calidad, suministro de agua.

\section{ABSTRACT}

The weak infrastructure developed around drinking water supply and basic sanitation in Colombian rural areas has led to unsatisfied basic needs of their inhabitants. Therefore, this research aims at validating the basic criteria for the design of a drinking water supply system in Socotá village, municipality of Apulo, using methods such as the inverse to the distance (IDW) to determine precipitation, the Thornthwaite method to calculate evapotranspiration, the geometric methodology for population projection, and the validation of the fulfillment of criteria for the selection of the most viable supply option for its subsequent design via Hazen-Williams equations. Results allowed to identify a need of 1,101 to $1,156 \mathrm{~mm} /$ year of bimodal character with periods of low water storage and a regular flow of $0.000295 \mathrm{~m}^{3} / \mathrm{s}$ for a total of 105 specific users. It was also established that the aqueduct Asuarcopsa is the best supply alternative, whose connection requires a pipe diameter equal to one inch and a storage tank of 10,195L. Overall results show deficiencies of availability, continuity and quality of direct water by the current supply system, thus the importance of this study.

Keywords: Drinking water, rural supply, availability, continuity, quality, water supply.

\section{INTRODUCCIÓN}

La inadecuada gestión del recurso hídrico ha provocado que varias regiones a nivel global no tengan un eficiente acceso al agua potable, a lo cual se suma el constante crecimiento demográfico, cuya consecuencia es el aumento de la demanda de agua dulce (por lo menos el $50 \%$ de la población mundial se abastece por medio de aguas subterráneas). Teniendo en cuenta esto, se estima que para 2030 se tendrá un déficit mundial de agua del $40 \%$ bajo un escenario en el que todo sigue en las condiciones actuales. Aunque el acceso al agua y al saneamiento básico es reconocido como un derecho humano, dicha problemática afectará principalmente a personas de escasos recursos, lo cual ya se evidencia en los cerca 1.200 millones de personas que habitan áreas donde el agua escasea y otros 1.100 millones que carecen de instalaciones necesarias para abastecerse de agua potable; hecho que se asocia a la presión no solo económica sino también sociopolítica y ambiental (Franek et al., 2015).

En Colombia, el recurso hídrico se ha visto afectado debido al desarrollo de actividades industriales y antropogénicas, amenazando en rangos altos y críticos de afectación a 152 subzonas hidrográficas de las 311 existentes (IDEAM, 2015). Además, el país cuenta con un escaso sistema de acueducto y alcantarillado que afecta especialmente a las zonas rurales y crea una brecha de $23 \%$ entre estas y las zonas urbanas, según

M U T I S" | Revista electrónica editada por la Facultad de Ciencias Naturales e Ingeniería de UTADEO 
lo estipula el Departamento Nacional de Planeación, DNP (2014).

Adicionalmente, como se muestra en el trabajo realizado por Carrasco-Mantilla (2016), la gestión del sector del agua potable y saneamiento básico en Colombia se ha visto afectada por la constante modificación de su estructura y de las organizaciones encargadas del desarrollo de las actividades encaminadas al progreso y el fortalecimiento del sector, en donde es posible evidenciar, además, que durante el desarrollo de todos estos cambios se ejecutaron políticas para garantizar la gestión equitativa de estas actividades en áreas urbanas y rurales del territorio nacional.

En este contexto, la situación a la cual se enfrenta la vereda Socotá del municipio de Apulo (Cundinamarca), permite demostrar que la equidad necesaria para garantizar el desarrollo de las áreas rurales del municipio no se está aplicando de manera óptima, puesto que, de acuerdo con datos proporcionados por la alcaldía de este municipio en su plan de desarrollo (Alcaldía Municipal de Apulo, 2016), el déficit de servicios públicos en el casco urbano es de $0,77 \%$, es decir, aproximadamente una de cada 100 viviendas no cuenta con servicios públicos completos, mientras que en lo rural (10,86 \%) 11 de cada 100 viviendas carecen de los servicios públicos básicos. Por otra parte, en cuanto a la cobertura de acueducto y alcantarillado, el $0,38 \%$ de las viviendas en el casco urbano carecen de esta dotación, mientras que lo mismo ocurre en el $68,4 \%$ de las viviendas de la zona rural, para una brecha de 68 puntos.

De acuerdo con lo anterior, es importante resaltar que actualmente los habitantes de la vereda Socotá se abastecen precariamente de agua mediante la recolección de aguas lluvias, motivo por el cual en época de verano se ven limitados en el acceso al agua y optan por recorrer largas distancias (con duración hasta de dos horas) para llegar a la capital del país (Bogotá D. C.) y obtener el recurso en condiciones apropiadas para el consumo humano. Así pues, es posible establecer estas limitaciones como condiciones de vulnerabilidad para los habitantes, evidenciadas en el incumplimiento de lo establecido en primera instancia dentro los artículos 334 y 365 al 367 de la Constitución Política de Colombia, en lo concerniente al papel del Estado frente al ofrecimiento de oportunidades de acceso a los servicios básicos, los cuales se consti- tuyen como inherentes a la función social del mismo, así como el bienestar general y el mejoramiento de la calidad de vida de la población a través de la atención prioritaria de las necesidades básicas insatisfechas en materia de agua potable y saneamiento básico; además de identificar la labor que debe ejercer el municipio en la prestación de los servicios públicos domiciliarios, la cual, a su vez, es contemplada dentro de la Ley 142 de 1994 y la Ley 715 de 2001.

Debido a lo anterior, en 2017, los habitantes de la vereda interpusieron un derecho de petición ante la Alcaldía del municipio de Apulo con el fin de obtener una solución para la problemática del abastecimiento de agua potable a la que se enfrentan. Sin embargo, la respuesta obtenida manifiesta que "Los recursos del municipio se invierten para dar cumplimiento a los planes, programas y proyectos contenidos en el plan de desarrollo" y aclara que "[...] la inversión en programas sociales no se focalizan en un sector específico del municipio (vereda Socotá)..." (García-Bernal, 2017). Por otra parte, para los habitantes es un hecho indignante y de total inequidad la existencia de gran opulencia en el terreno que se encuentra al otro lado del río Bogotá, justo al frente de la vereda, donde está ubicado el club campestre "Mesa de Yeguas", el cual cuenta con un lago artificial con capacidad para almacenar $4 \mathrm{mi}$ llones de litros cúbicos de agua y en el que se practican diferentes modalidades de deportes náuticos.

Por lo anterior, este proyecto tiene la finalidad de realizar un análisis de viabilidad que permita identificar y diseñar los principales parámetros de un sistema de abastecimiento de agua potable para la vereda Socotá, municipio de Apulo, que cumpla con los criterios de disponibilidad, continuidad y calidad para mejorar la calidad de vida de los habitantes de esta vereda y reducir la brecha en el acceso al servicio de abastecimiento de agua potable existente entre el casco urbano y rural.

\section{MATERIALES Y MÉTODOS}

\section{Sitio de estudio}

El municipio de Apulo está ubicado en el departamento de Cundinamarca, limitando al norte con el municipio de Quipile y Jerusalén, al sur con el municipio de Viotá, al oriente con el municipio de Anapoima y al occidente con el municipio de Tocaima. Apulo está 
conformado por 28 veredas, divididas en 4 sectores, entre las cuales se encuentra la vereda Socotá, perteneciente al sector 3 , de acuerdo con el plan de desarrollo del municipio, localizada al oriente, con coordenadas geográficas $4^{\circ} 30^{\prime} 50^{\prime \prime} \mathrm{N}$ y $74^{\circ} 33^{\prime} 20^{\prime \prime} \mathrm{W}$, y colindante con el río Bogotá. Esta vereda posee un área de $6,73 \mathrm{~km}^{2}$, se encuentra a una altitud entre 500 y 800 m s. n. m. (figura 1), posee un clima tropical con temperatura promedio de $27{ }^{\circ} \mathrm{C}$ y una precipitación media anual de $1.130 \mathrm{~mm}$. En la actualidad, se registran 98 habitantes y 44 viviendas, las cuales no cuentan con una conexión vial directa a la cabecera municipal de Apulo. El ingreso a la vereda se realiza a través de una carretera sin pavimentar en conexión con el municipio de Anapoima ubicada al nororiente de Socotá.

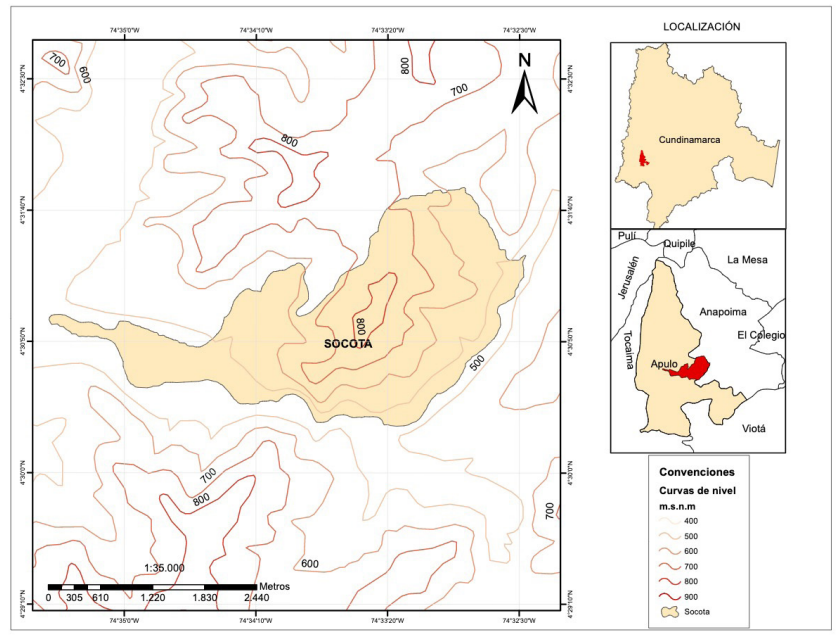

Figura 1. Ubicación de la zona de estudio. Fuente: elaboración propia.

\section{Datos}

Para el desarrollo de la metodología propuesta se recolectó información a través de una base de datos creada tras una solicitud realizada al Instituto de Hidrología, Meteorología y Estudios Ambientales (IDEAM) sobre las estaciones hidrometeorológicas cercanas a la vereda, con lo cual se logró obtener datos de precipitación y temperatura necesarios para conocer la evapotranspiración a partir de la implementación del método de Thornthwaite, de acuerdo con la metodología planteada más adelante.

Posteriormente, se recolectaron datos sobre la variación de la población de la vereda, cuyo objetivo es el cálculo de la proyección de población futura para determinar la demanda de agua. Las fuentes de información se describen con mayor detenimiento a continuación:

- Estaciones hidrometeorológicas: se escogieron las 9 estaciones hidrometeorológicas del IDEAM más cercanas a la zona de estudio, entre las que se encuentran ESC Samper Madrid Victoria La, Col. Francisco José De Caldas, Anclaje 14, Mesitas, Darío Valencia, Mesa La, San Gregorio y Socotá.

Es importante tener en cuenta que los datos sobre precipitación y temperatura recolectados de las estaciones hidrometeorológicas corresponden a cifras mensuales y abarcan el período comprendido entre 1987 y 2014.

- Población: la obtención de esta información fue posible gracias a dos fuentes importantes. La primera de ellas es el esquema de ordenamiento territorial (EOT), en el cual se especifican los datos de los años 1985 y 1998. La segunda corresponde al departamento del Sisbén, el cual proporcionó información para el año 2018 durante las visitas realizas a la alcaldía del municipio.

\section{Metodología}

Para el desarrollo del presente estudio se establecieron 4 fases: (i) análisis hidrológico y topográfico, (ii) estudio de la demanda de agua, (iii) alternativas de abastecimiento de agua potable y (iv) diseño de la alternativa seleccionada, en las cuales se aplicaron diversos métodos que permitieron desarrollar una investigación descriptiva y analítica con enfoque cuantitativo para la identificación de la alternativa que se adapte de forma óptima a las necesidades de la comunidad de la vereda Socotá, tomando como referencia la guía desarrollada por el Banco Nacional de Obras y Servicios Públicos, BanObras (2010).

\section{Análisis hidrológico y topográfico}

El análisis hidrológico para la zona de estudio inicia con el establecimiento de las condiciones actuales de la vereda Socotá a través de la identificación tendencial de precipitación, donde, con los datos obtenidos de las estaciones hidrometeorológicas del IDEAM, se realiza una interpolación por el método inverso a la distancia (IDW), que consiste en asignar el peso de forma inversamente proporcional a la distancia (a mayor distancia, menor peso) a partir del coeficiente poten- 
cia $\beta$ (Díaz-Padilla et al., 2008), mediante el uso del software de sistemas de información geográfica ArcGIS.

Posteriormente, se evalúa la evapotranspiración a través de la aplicación del método de Thornthwaite, tomando como base metodológica lo propuesto por Bustamante et al. (2013), cuya aplicación permite el cálculo de la evapotranspiración potencial mensual de una superficie de referencia cubierta de césped con base en la temperatura media mensual, con el fin de estimar la necesidad de agua del lugar (Marín, 2010). Adicionalmente, se requiere un factor de ajuste que relaciona la altitud de la zona de estudio $\left(4^{\circ} 30^{\prime} 50^{\prime \prime} \mathrm{N}\right)$ y la insolación teórica; este factor se puede encontrar la obra de Quereda (2005).

La evapotranspiración potencial se expresa como:

$$
E T P=16(10 T / I)^{a} \quad(\text { Ec.1 })
$$

Donde:

ETP: evapotranspiración potencial mensual no corregida ( $\mathrm{mm} / \mathrm{mes})$

$\mathrm{T}$ : temperatura media mensual en ${ }^{\circ} \mathrm{C}$

I: índice de calor anual siendo:

$$
\mathrm{I}=\Sigma(T / 5)^{1.514} \quad(\text { Ec. } 2)
$$

a: exponente empírico en función de I, donde:

$$
a=6.75 \times\left. 10^{-7}\right|^{3}-7.71 \times\left. 10^{-5}\right|^{2}+1.79 \times 10^{-2} I+0.49239
$$

(Ec. 3)

Para obtener la evapotranspiración potencial ajustada, se divide la ETP con el factor de ajuste según el mes; este factor tiene en cuenta la latitud y el número de horas de insolación teórica (Montaner, 1988)

$$
\mathrm{ETP}_{\mathrm{a}}=\mathrm{ETP} / \text { factor de ajuste }
$$

A continuación, se debe calcular la precipitación útil para cada mes $(\Delta)$. Este cálculo ayuda a obtener la capacidad de almacenamiento, el déficit y el exceso de agua que presenta cada mes:

$$
\Delta=\mathrm{P}-\mathrm{ETPa}_{\mathrm{a}} \quad \text { (Ec. 5) }
$$

Para finalizar, se calcula la evapotranspiración real (ETR) evaluando los siguientes criterios:

$$
\begin{aligned}
\text { Si } \mathrm{P}>=\mathrm{ETP}_{\mathrm{a}} \text { entonces ETR } & =\mathrm{ETPa}_{\mathrm{a}} \quad \text { (EC. 6) } \\
\text { Si } \mathrm{P}<\mathrm{ETP}_{\mathrm{a}} \text { entonces ETR } & =\mathrm{P}+\left(\mathrm{P}-\mathrm{ETP}_{\mathrm{a}}\right)
\end{aligned}
$$

Donde:

$\mathrm{P}:$ precipitación ( $\mathrm{mm} / \mathrm{mes}$ )

ETR: evapotranspiración real ( $\mathrm{mm} / \mathrm{mes})$

ETPa: evapotranspiración potencial mensual ajustada (mm/mes)

Para el análisis topográfico se determina el perímetro y área de la vereda por medio del Software ArcGIS, según la metodología utilizada por Aliaga (2006), en la cual se realiza una superposición de imágenes y digitalización de la zona de estudio. La pendiente se calcula según el método tradicional topográfico, donde se relaciona el desnivel y la distancia horizontal del terreno, dada por la expresión:

$$
\text { Dv/Dh } * 100=\text { Pendiente } \% \quad(\text { Ec. } 7)
$$

Donde:

Dv: distancia vertical del terreno

Dh: distancia horizontal del terreno

\section{Demanda de agua}

Esta fase pretende calcular los valores mínimos que requiere un habitante de la vereda Socotá para satisfacer sus necesidades. Para esto se tuvo en cuenta lo establecido en la Resolución 0330 de 2017 que adopta el Reglamento Técnico para el Sector de Agua potable y Saneamiento Básico (RAS), según lo descrito por López (2003).

A través del método geométrico se calcula la proyección de la población teniendo en cuenta los datos proporcionados por el Sisbén y el EOT de Apulo, junto con el porcentaje de crecimiento del departamento de Cundinamarca (2\%), a partir de la expresión:

$$
P_{f}=P_{u c}(1+r)^{T f-T u c} \quad(\text { Ec. } 8)
$$

La tasa de crecimiento anual se obtiene a través de:

$$
r=(\text { Puc } / \text { Pci })^{(1 /(\text { Tuc-Tci)) }-1}
$$

Donde: 
$r$ : tasa de crecimiento anual en forma decimal

Pf: población correspondiente al año para el que se requiere realizar la proyección (habitantes)

$P_{u c}$ : población correspondiente a la proyección del último año (habitantes)

$P_{\mathrm{ci}}$ : población correspondiente al censo inicial con información (habitantes)

Tuc: año correspondiente al último año proyectado del último año

$\mathrm{T}_{\mathrm{f}}$ : año al cual se quiere proyectar la información

La determinación de la dotación neta, correspondiente a la cantidad mínima de agua requerida por habitante, se estableció según la altura promedio al nivel del mar. Por su parte, la dotación bruta se obtiene a partir de la relación de la dotación neta y las pérdidas técnicas, expresada como:

$$
D_{\text {Bruta }}=(\text { dneta/(1-\%p)) } \quad \text { (Ec. 10) }
$$

Donde:

$D_{\text {Bruta: }}$ dotación bruta (L/hab*día)

$\mathrm{d}_{\text {neta: }}$ dotación neta (L/hab*día)

\%p: porcentaje de pérdidas técnicas máximas para diseño (no debe superar $25 \%$ )

Finalmente, para obtener la demanda de agua de la población proyectada a 25 años se calculan los caudales requeridos de la siguiente forma.

El caudal medio diario (Qmd) en L/s, se expresa como:

$$
\text { Qmd } \left.=\left(p * D_{\text {Bruta }}\right) / 86400 \quad \text { (Ec. } 11\right)
$$

Para un sistema nuevo, el caudal máximo diario (QMD) en L/s se expresa como:

$$
\left.\mathrm{QMD}=\mathrm{Qmd}{ }^{*} 1.30 \quad \text { (Ec. } 12\right)
$$

El caudal máximo horario (QMH) en L/s, para sistemas nuevos se expresa como:

$$
\mathrm{QMH}=\mathrm{QMD} * 1.6 \quad(\text { Ec. } 13)
$$

\section{Viabilidad de abastecimiento de agua}

Para el análisis de viabilidad se seleccionaron tres posibles fuentes de abastecimiento de agua potable para la vereda Socotá: acueductos municipales, acueductos veredales y aguas subterráneas, teniendo en cuenta el desarrollo metodológico de Angarita-Zambrano (2016).

Es importante aclarar que para la selección de las alternativas aquí dispuestas se tuvieron en cuenta las siguientes atribuciones:

1. Acueducto Empoapulo S.A. E.S.P, municipio de Apulo: dada la ubicación geográfica de la vereda y su correspondencia administrativa con el municipio de Apulo, es responsabilidad directa del mismo prestar los servicios públicos domiciliaros a todos sus habitantes, de acuerdo con lo establecido dentro de la Ley 142 de 1994 y la Ley 715 de 2001, razón por la cual se establece como alternativa de abastecimiento.

2. Acueducto Aguas del Tequendama S.A. E.S.P, municipio de Anapoima: teniendo en cuenta la conectividad inmediata que posee la vereda Socotá con el municipio de Anapoima, y de acuerdo con la información suministrada por los habitantes de la vereda en relación con la ejecución de actividades diarias como el trabajo, la compra de los alimentos, la educación y la atención médica en este municipio.

3. Acueducto Asuarcopsa (Asociación de Usuarios del Acueducto Regional de Anapoima), municipio de Anapoima, para el cual se tuvieron en cuenta los siguientes factores:

- La petición realizada por la comunidad tras acercamientos de los representantes de la junta de acción comunal (JAC) de la vereda Socotá con los encargados del acueducto, producto de las observaciones positivas realizadas por los usuarios acerca de la calidad del servicio prestado por el acueducto a veredas vecinas.

- El conocimiento del acueducto por parte del ingeniero Jesús Ernesto Torres, quien participó y asesoró el desarrollo del proyecto "Diagnóstico y optimización del sistema de acueducto veredal Asuarcopsa de Anapoima entre la bocatoma y la planta de tratamiento". 
- El reporte de prestador de servicio obtenido del Sistema de Información de Agua Potable y Saneamiento Básico (SIASAR), al cual pertenece Colombia y que tiene como objetivo desarrollar la capacidad del personal técnico en cada país para planificar, monitorear y gestionar el sector del agua y el saneamiento rural de forma efectiva, siendo diseñado como un modelo conceptual de análisis y monitoreo de información en este sector, estandarizando lo regionalizado y lo público. En este reporte se específica que el acueducto Asuarcopsa cuenta con el volumen suficiente para cubrir la demanda requerida, además de contar con la estructura necesaria y encontrarse en las condiciones apropiadas para la producción de agua potable (SIASAR, s.f)

4. Finalmente, se tiene en cuenta la alternativa de abastecimiento por medio de aguas subterráneas, atendiendo la petición de los habitantes de la vereda, debido a que a partir del desarrollo de un estudio tradicional realizado por la comunidad se obtuvo información sobre la posible existencia de agua a una profundidad en un rango de 6 a 15 metros, con posterior desarrollo de excavaciones y verificación de la existencia de aguas subterráneas.

De acuerdo con lo anterior se prevé un estudio de la caracterización de la calidad del agua según los criterios establecidos en la Resolución 2115 de 2007, en el cual se tomará una muestra de $1.000 \mathrm{ml}$ del agua de la excavación y se procederá a evaluar el $\mathrm{pH}$ in situ por medio de cinta indicadora. Posteriormente, de manera ex situ, el $\mathrm{pH}$ se evaluará con un $\mathrm{pH}$ metro con precisión de 0,01 unidades de $\mathrm{pH}$ y la conductividad de forma directa con un conductímetro; ambos equipos se calibrarán con soluciones amortiguadoras de 4,00 y 7,00 unidades de $\mathrm{pH}$. Las características químicas restantes se evaluarán por medio de espectrofotometría ultravioleta en laboratorio, de conformidad con la metodología propuesta por Pérez-Moreno et al. (2003).

En consecuencia, para determinar la viabilidad del suministro por parte de los acueductos, se realiza la revisión de los requisitos establecidos por los mismos para la evaluación de la disponibilidad de agua con el fin de obtener información de la red de distribución y el análisis del suministro.
Para evaluar la alternativa del agua subterránea se recolecta información sobre los pozos registrados en la base de datos disponible de la Corporación Autónoma Regional (CAR) de Cundinamarca y la investigación sobre la presencia de acuíferos a fin de identificar su existencia dentro o en zonas aledañas a la vereda.

A partir de la información recolectada se realiza un análisis de viabilidad en el que se tiene en cuenta los siguientes criterios: (i) disponibilidad, (ii) calidad, (iii) continuidad y (iv) distancia desde la fuente abastecedora hasta la vereda Socotá, partiendo del concepto de seguridad hídrica expuesto por Peña (2016, p. 7), que "Consiste en tener: una disponibilidad de agua que sea adecuada, en cantidad y calidad, para el abastecimiento humano, los usos de subsistencia, la protección de los ecosistemas y la producción", y por Martínez-Austria (2013, p. 165), quien afirma que la seguridad hídrica es "[...] aquella que garantiza agua suficiente en calidad y cantidad para los diversos usos, a precios asequibles y en equidad". Así mismo, se tuvo en cuenta lo dispuesto en el artículo 11 de la Ley 142 de 1994 sobre la función social de la propiedad en las entidades prestadoras de servicios públicos. A partir de lo anterior, se determina el cumplimiento o incumplimiento de los criterios a través de una matriz de validación con el objetivo de identificar la alternativa de abastecimiento que permita satisfacer la necesidad de agua potable y así mejorar la calidad de vida de los habitantes de la vereda.

\section{Diseño de la alternativa}

Se identifica la necesidad de verificar la información obtenida en el trabajo de campo para realizar el perfil topográfico a través de los software Google Earth y AutoCAD, con los cuales se busca determinar longitudes y desniveles del terreno y tipo de sistema de conducción requerido, junto con sus respectivos accesorios, para el posterior cálculo del diámetro de la tubería según la ecuación de Hazen-Williams (López, 2003), la cual se expresa como:

$$
D=\left[\frac{Q}{0.2785 * C * S^{0.54}}\right]^{1 / 2.63}
$$

Donde:

D: diámetro $(\mathrm{m})$

Q: caudal $\left(\mathrm{m}^{3} / \mathrm{s}\right)$

C: coeficiente de rugosidad de Hazen-Williams 
$R$ : radio hidráulico $=A_{\text {mojada }} / P_{\text {mojado }}(m)$

S: pendiente del terreno $=h_{\text {disponible }} /$ longitud tubería

Adicionalmente, se determina el volumen del tanque requerido para el almacenamiento de agua en la vereda Socotá, como se muestra en la siguiente expresión:

$$
\mathrm{V}=1.2 * \mathrm{~V}_{\mathrm{CMH}} * \mathrm{Q} \quad(\mathrm{Ec} .15)
$$

Donde:

V: volumen del tanque $\left(\mathrm{m}^{3}\right)$

$\mathrm{V}_{\text {смн: }}$ volumen del consumo máximo horario

Q: caudal ( $\mathrm{m}^{3} /$ día)

De acuerdo con lo establecido en el RAS, para el valor de $\mathrm{V}_{\mathrm{CMH}}$ se utiliza el porcentaje empírico para poblaciones pequeñas, el cual corresponde a 1/3.

\section{RESULTADOS}

A continuación, se reportan los resultados obtenidos de acuerdo con la estructura de la metodología planteada anteriormente.

\section{Análisis hidrológico y topográfico}

\section{Precipitación}

De acuerdo con la metodología establecida para el cálculo de la precipitación anual y el análisis realizado en 2018 , se evidenció que Socotá posee una precipitación entre 1.101 y 1.156 mm/año, como se observa en la figura 2.
De acuerdo con la estación más cercana a la vereda (ESC Samper Madrid), la precipitación a lo largo del año muestra un comportamiento bimodal que exhibe un máximo de precipitación en marzo, abril, octubre y noviembre y un mínimo en julio y agosto, donde la precipitación no sobrepasa $40 \mathrm{~mm}$ (figura 3).

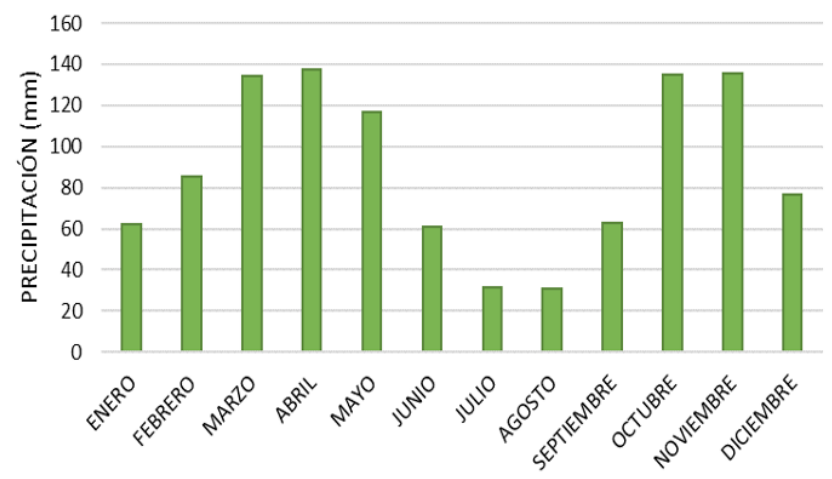

Figura 3. Comportamiento anual de la precipitación. Fuente: elaboración propia.

\section{Evapotranspiración real}

Consecuentemente, por medio de la aplicación del método de Thornthwaite se realizó el balance hídrico (tabla 1), evidenciando que la vereda posee un déficit de agua en los meses de febrero, marzo, junio, julio, agosto y septiembre; períodos secos que se establecen como críticos debido a las dificultades de acceso al recurso hídrico y que afectan el abastecimiento por medio de agua lluvia. Además, fue posible evidenciar que solo en el mes de abril existe un delta de almacenamiento, llegando a $800 \mathrm{~mm}$, y que octubre exhibe un almacenamiento moderado.

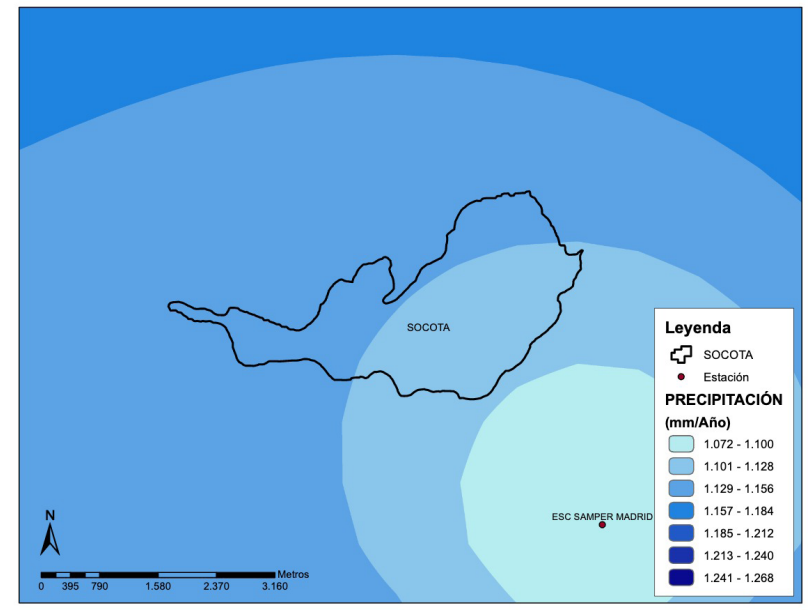

Figura 2. Interpolación por IDW para precipitación anual (2018). Fuente: elaboración propia. 
Tabla 1. Balance Hídrico Estación Parcial

\begin{tabular}{|c|c|c|c|c|c|c|c|c|c|c|c|c|c|}
\hline & Ene & Feb & Mar & Abr & May & Jun & Jul & Ago & Sep & Oct & Nov & Dic & Total \\
\hline $\begin{array}{l}\text { Precipitación } \\
\qquad(\mathrm{Pm})\end{array}$ & 107,10 & 60,80 & 107,30 & 398,30 & 69,70 & 18,20 & 36,80 & 51,10 & 53,00 & 256,50 & 112,70 & 59,20 & $1.330,70$ \\
\hline ETP & 105,30 & 96,44 & 136,23 & 142,02 & 172,87 & 188,66 & 199,81 & 210,37 & 199,87 & 153,82 & 148,59 & 167,27 & $1.921,25$ \\
\hline $\begin{array}{l}\text { Factor de } \\
\text { ajuste }\end{array}$ & 1,02 & 0,93 & 1,03 & 1,02 & 1,06 & 1,03 & 1,06 & 1,05 & 1,01 & 1,03 & 0,99 & 1,02 & \\
\hline ETPa & 103,24 & 103,70 & 132,26 & 139,24 & 163,09 & 183,16 & 188,50 & 200,36 & 197,90 & 149,34 & 150,09 & 163,99 & $1.874,84$ \\
\hline$\Delta$ & 3,86 & $-42,90$ & $-24,96$ & 259,06 & $-93,39$ & $-164,96$ & $-151,70$ & $-149,26$ & $-144,90$ & 107,17 & $-37,39$ & $-104,79$ & - \\
\hline $\begin{array}{l}\text { Variación } \\
\text { (Alm) }\end{array}$ & 3,86 & 0,00 & 0,00 & 100,00 & 6,61 & 0,00 & 0,00 & 0,00 & 0,00 & 100,00 & 62,61 & 0,00 & - \\
\hline Deficit & 0,00 & $-39,00$ & $-63,96$ & 0,00 & 0,00 & $-158,35$ & $-151,70$ & $-149,26$ & $-144,90$ & 0,00 & 0,00 & $-42,18$ & $-749,34$ \\
\hline Exceso & 0,00 & 0,00 & 0,00 & 159,06 & 0,00 & 0,00 & 0,00 & 0,00 & 0,00 & 7,17 & 0,00 & 0,00 & 166,23 \\
\hline$\Delta$ Alm & 3,90 & $-3,90$ & 0,00 & 100,00 & $-93,39$ & $-6,61$ & 0,00 & 0,00 & 0,00 & 100,00 & $-37,39$ & $-62,61$ & - \\
\hline ETR $(\mathrm{mm})$ & 103,24 & 64,70 & 132,26 & 139,24 & 163,09 & 24,81 & 36,80 & 51,10 & 53,00 & 149,34 & 150,09 & 121,81 & $1.189,43$ \\
\hline
\end{tabular}

Fuente: elaboración propia.

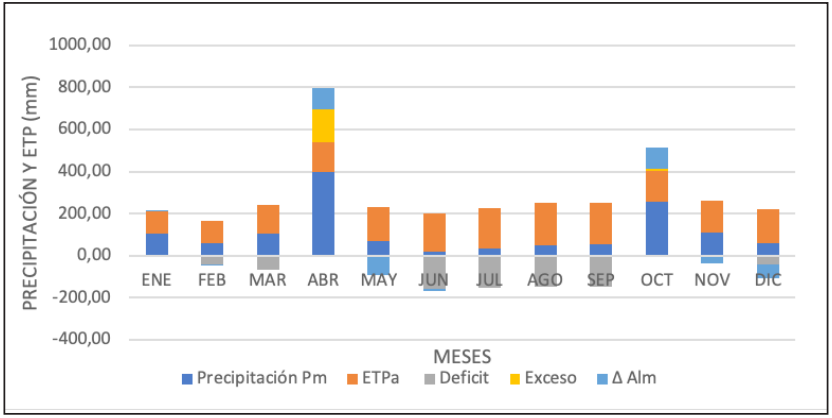

Figura 4. Representación gráfica del balance hídrico estación parcial. Fuente: elaboración propia.

\section{Área y perímetro}

Por medio de la digitalización de la vereda en el software ArcGIS se obtiene como resultado un área de $7,1 \mathrm{Km}^{2}$ y un perímetro de $16,2 \mathrm{Km}$, evidenciando que la vereda ocupa $5,8 \%$ del territorio total del municipio de Apulo (12.240 ha).

\section{Pendiente}

A partir de los cálculos realizados, la vereda posee por el costado oriental una pendiente de $38,63 \%$, mientras que por el costado oriental es de $21,59 \%$, por lo cual es posible determinar, según lo establecido por el Instituto Geográfico Agustín Codazzi (2014), que el territorio de la vereda cuenta con una pendiente fuertemente ondulada y moderadamente quebrada.

\section{Demanda de agua}

A partir de la investigación realizada en las diferentes entidades mencionadas se obtuvieron los datos relacionados en la figura 5 , donde se evidencia un amplio decrecimiento de la población de la vereda.

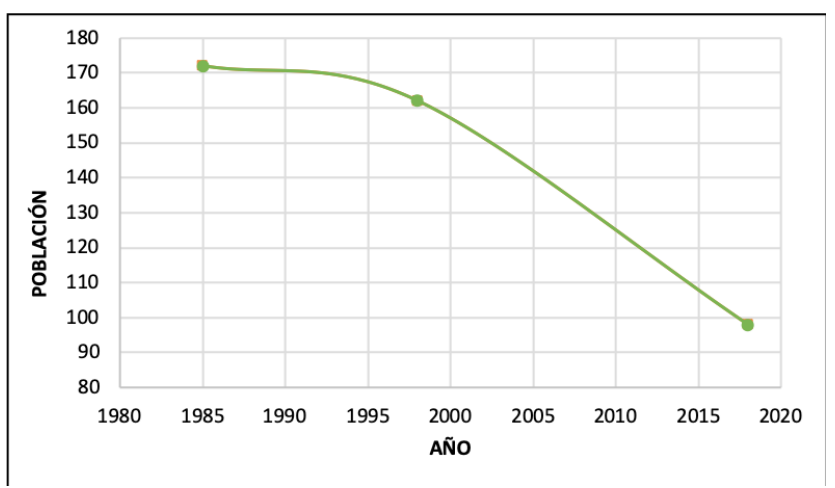

Figura 5. Evolución poblacional 1985-2018.

Fuente: elaboración propia.

Con la información recolectada se realizó la proyección poblacional para los años 2030 y 2043 (figura 6), lo cual permitió determinar las dotaciones y caudales requeridos. Con esta información fue posible realizar el diseño de la tubería necesaria, como se detalla en la tabla 2. 


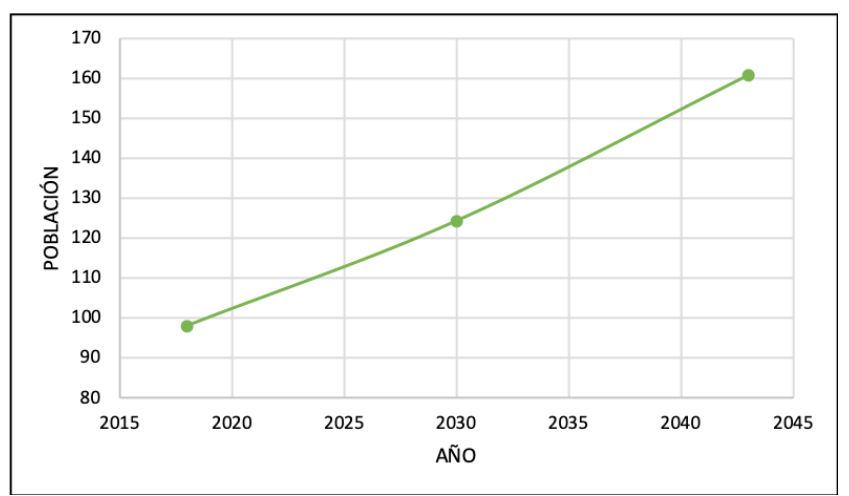

Figura 6. Proyección poblacional total Fuente: elaboración propia.

Tabla 2. Determinación de caudales

\begin{tabular}{cc}
\hline Dotación neta (L/hab*día) & 140 \\
\hline Dotación bruta (L/hab*día) & 186,67 \\
\hline Qmd (L/s) & 0,347 \\
\hline QMD (L/s) & 0,452 \\
\hline QMH (L/s) & 0,723 \\
\hline
\end{tabular}

Fuente: elaboración propia.

\section{Usuarios}

Por medio del trabajo realizado en campo fue posible identificar que, debido a deficiencias en la organización y administración de la vereda, actualmente cerca de 16 predios han solicitado el suministro de agua potable, por lo que es necesario recalcular la proyección (tabla 3 ) y el caudal requerido para el abastecimiento de los usuarios potenciales (tabla 4).

Tabla 3. Usuarios potenciales

\begin{tabular}{cc}
\hline Año & Población \\
\hline 2018 & 64 \\
\hline 2030 & 81 \\
\hline 2043 & 105 \\
\hline
\end{tabular}

Fuente: elaboración propia.
Tabla 4. Caudal para usuarios potenciales

\begin{tabular}{cc}
\hline Dotación neta (L/hab*día) & 140 \\
\hline Dotación bruta (L/hab*día) & 186,67 \\
\hline Qmd (L/s) & 0,227 \\
\hline QMD (L/s) & 0,295 \\
\hline QMH (L/s) & 0,472 \\
\hline
\end{tabular}

Fuente: elaboración propia.

\section{Viabilidad de abastecimiento}

\section{Acueductos municipales}

A través de la información obtenida del acueducto Aguas Tequendama S.A. E.S.P, se evidencia la necesidad de incurrir en gastos por parte de los habitantes de la vereda para posibilitar el estudio de abastecimiento de agua potable. Por esta razón, se tiene en cuenta la información obtenida mediante investigación bibliográfica y lo reportado en el trabajo de Botero-Monsalve et al., (2017, p. 16), quienes afirman que:

En total, el municipio tiene la capacidad de recibir $38 \mathrm{l} / \mathrm{s}$, pero en la conducción desde Tena hasta Anapoima, el sistema pierde $15 \mathrm{l} / \mathrm{s}$ debido a conexiones fraudulentas realizadas en el área rural. De esta forma no es posible garantizar suministro continuo para el municipio.

A lo anterior, se suma lo descrito en la evaluación integral de prestadores de la Empresa Regional de Aguas del Tequendama S.A. E.S.P (Superintendencia de Servicios Públicos Domiciliarios, 2019), en donde se promulga que "[...] la continuidad para los años 2017 y 2018 presuntamente no cumplió con lo dispuesto en el anexo técnico de los Contratos de Condiciones Uniformes. Adicionalmente, la continuidad clasificó como insuficiente de acuerdo con la Resolución 2115 de 2007". Esto permite identificar la falta de disponibilidad de agua por parte de este acueducto para el abastecimiento de la vereda Socotá; además de que este se encuentra a una distancia de 2,31 km del lugar en el que se proyecta la ubicación del tanque enunciado en el punto 10 de la tabla 7.

Por otro lado, de acuerdo con la respuesta al derecho de petición enviado por los habitantes de la vereda a la alcaldía de Apulo, se evidencia que la alcaldía (ente 
administrativo coordinador de la gestión de Empoapulo) no posee los recursos financieros necesarios para la ampliación del acueducto Empoapulo S.A. E.S.P, requerida para el abastecimiento de agua potable, puesto que este rubro no se contempló en el plan de desarrollo. Adicionalmente, la distancia existente entre este acueducto y la ubicación de la proyección del tanque de almacenamiento y distribución es de 4,75 km.

\section{Acueducto veredal}

En conformidad con los datos registrados en la tabla 7, la distancia existente entre el tanque proyectado para la vereda Socotá (punto 10) y el último punto de la red de distribución del acueducto veredal Asuarcopsa (punto 4), ubicado en el municipio de Anapoima, es de 0,95 km. Además, tras acercamientos entre la JAC de Socotá y los administradores del acueducto, se identifica la disponibilidad de agua para de suministro del servicio a la vereda.

\section{Aguas subterráneas}

Se evidenció que no existen pozos registrados en la vereda Socotá o en zonas aledañas a esta. Sin embargo, se identificó la existencia del acuífero Purificación-Saldaña.

De acuerdo con lo anterior, y de conformidad con la información obtenida por medio de la comunidad, se realiza la caracterización de la calidad del agua presente en la zona, obteniendo los resultados que se muestran en la tabla 5, donde el color rojo representa las concentraciones de los contaminantes por encima de las permitidas y el naranja representa las concentraciones de contaminantes próximas a sobrepasar los límites establecidos en la Resolución 2115 de 2007 del Ministerio de la Protección Socia y el Ministerio de Ambiente, Vivienda y Desarrollo Territorial.

Es importante tener en cuenta que la muestra de agua fue obtenida en la excavación realizada por los habitantes de la vereda, la cual cuenta con un área de 2,5 $\mathrm{m}^{2}$ y un nivel freático a 5 metros de profundidad, aproximadamente, que se localiza en las coordenadas $4^{\circ} 30^{\prime} 57.8^{\prime \prime} \mathrm{N} 74^{\circ} 32^{\prime} 52.7^{\prime \prime} \mathrm{W}$. Adicionalmente, esta no posee protección frente a la caída de materia orgánica (hojas, ramas, etc.), ni refuerzo de las paredes que evite el derrumbe de las mismas o el desprendimiento de suelo, razón por la cual se tuvo la precaución de tomar la muestra a una profundidad de 1 metro bajo la superficie del agua.
Tabla 5. Caracterización del agua subterránea en la vereda Socotá

\begin{tabular}{|c|c|c|c|}
\hline \multicolumn{4}{|c|}{ Muestra de agua subterránea } \\
\hline Parámetro & Rango & ación & Valor \\
\hline Sabor & \multicolumn{2}{|c|}{ Aceptable } & - \\
\hline Olor & \multicolumn{2}{|c|}{ Aceptable } & Aceptable \\
\hline Temperatura & \multicolumn{2}{|c|}{${ }^{\circ} \mathrm{C}$} & 16,1 \\
\hline $\mathrm{pH}$ in situ & \multirow{2}{*}{\multicolumn{2}{|c|}{$\begin{array}{c}6,5-9,0 \\
7,29\end{array}$}} & 8 \\
\hline pH ex situ & & & \\
\hline Color & $<15$ & UPC & 15 \\
\hline Turbiedad & $<2$ & UNT & 26,5 \\
\hline Conductividad & $<1.000$ & $\mu S / \mathrm{cm}$ & 2.977 \\
\hline Dureza & $<300$ & $\mathrm{mg} / \mathrm{L}$ & 347,6 \\
\hline Alcalinidad & $<200$ & $\mathrm{mg} / \mathrm{L}$ & 332,2 \\
\hline Sulfatos & $<250$ & $\mathrm{mg} / \mathrm{L}$ & $>265$ \\
\hline Cloruros & $<250$ & $\mathrm{mg} / \mathrm{L}$ & 8,37 \\
\hline Nitritos & $<0,1$ & $\mathrm{mg} / \mathrm{L}$ & 0,11 \\
\hline Nitratos & $<10$ & $\mathrm{mg} / \mathrm{L}$ & 3,3 \\
\hline Calcio & $<60$ & $\mathrm{mg} / \mathrm{L}$ & $>160$ \\
\hline Zinc & $<3$ & $\mathrm{mg} / \mathrm{L}$ & 0,15 \\
\hline Fosfatos & $<0,5$ & $\mathrm{mg} / \mathrm{L}$ & 0,4 \\
\hline Hierro & $<0,3$ & $\mathrm{mg} / \mathrm{L}$ & 0,123 \\
\hline Manganeso & $<0,1$ & $\mathrm{mg} / \mathrm{L}$ & 0,98 \\
\hline Aluminio & $<0,2$ & $\mathrm{mg} / \mathrm{L}$ & $<0,020$ \\
\hline
\end{tabular}

Fuente: elaboración propia con datos de la Resolución 2115 de 2007.

\section{Validación de criterios}

Teniendo en cuenta la información recolectada sobre las alternativas de abastecimiento seleccionadas para el suministro de agua potable a la vereda Socotá, se evalúa el cumplimiento de los criterios establecidos en la metodología para el desarrollo del análisis de viabilidad. De acuerdo con lo anterior, se desarrolla la validación presentada en la tabla 6 .

Según lo expresado en la tabla 6 , se selecciona como la alternativa más viable para el abastecimiento de agua potable el acueducto veredal Asuarcopsa, teniendo en cuenta que cumple con todos los criterios establecidos y que se encuentra a una distancia considerablemente corta hasta el punto en el que se proyectó el tanque en la vereda Socotá. 
Tabla 6. Validación de cumplimento de criterios

\begin{tabular}{|c|c|c|c|c|c|c|c|c|}
\hline \multirow{4}{*}{ Criterios de viabilidad } & \multicolumn{8}{|c|}{ Alternativas de abastecimiento } \\
\hline & \multicolumn{4}{|c|}{ Acueductos municipales } & \multirow{2}{*}{\multicolumn{2}{|c|}{$\begin{array}{l}\text { Acueducto veredal } \\
\text { Asuarcopsa }\end{array}$}} & \multirow{2}{*}{\multicolumn{2}{|c|}{ Aguas subterráneas }} \\
\hline & \multicolumn{2}{|c|}{$\begin{array}{l}\text { Empoapulo } \\
\text { S.A. E.S.P. }\end{array}$} & \multicolumn{2}{|c|}{$\begin{array}{c}\text { Aguas del Tequendama } \\
\text { S.A. E.S.P. }\end{array}$} & & & & \\
\hline & Cumple & No cumple & Cumple & No cumple & Cumple & No cumple & Cumple & No c umple \\
\hline Disponibilidad & & $x$ & & $x$ & $x$ & & $x$ & \\
\hline Calidad & $x$ & & $x$ & & $x$ & & & $x$ \\
\hline Continuidad & & $x$ & & $x$ & $x$ & & $x$ & \\
\hline $\begin{array}{l}\text { Distancia (Alternativa - } \\
\text { Proyección de tanque) }\end{array}$ & & $5 \mathrm{~km}$ & & $1 \mathrm{~km}$ & & $5 \mathrm{~km}$ & & $79 \mathrm{~km}$ \\
\hline
\end{tabular}

Fuente: elaboración propia.

\section{Diseño}

El acueducto Asuarcopsa "...cuenta con 570 suscriptores, con un promedio de 5 personas por punto de agua para una población de 2850 personas..." (Huérfano-Maciado \& Segura-Garzón, 2019, p. 34), que se encuentran distribuidos en las veredas Plenitud, Santa Ana, Providencia Mayor, Providencia García, El Cabral,
El Consuelo Alto, El Consuelo Bajo y Santa Rosa, municipio de Anapoima, esta última con una conexión con la vereda Socotá.

Para el diseño de la alternativa de abastecimiento fue necesario recolectar las coordenadas de los puntos estratégicos que se muestran en la tabla 7.

Tabla 7. Ubicación de los principales puntos para el diseño.

\begin{tabular}{cccc}
\hline Punto & Descripción & Coordenada X & Coordenada Y \\
\hline 1 & Vía principal de Anapoima & $74^{\circ} 32^{\prime} 5.58^{\prime \prime} \mathrm{O}$ & $4^{\circ} 32^{\prime} 59.68^{\prime \prime} \mathrm{N}$ \\
\hline 2 & Entrada a las veredas & $74^{\circ} 32^{\prime} 22.77^{\prime \prime} \mathrm{O}$ & $4^{\circ} 32^{\prime} 5.87^{\prime \prime} \mathrm{N}$ \\
\hline 3 & Vía Asuarcopsa & $74^{\circ} 32^{\prime} 16.97^{\prime \prime} \mathrm{N}$ & $4^{\circ} 31^{\prime} 39.89^{\prime \prime} \mathrm{N}$ \\
\hline 4 & Fin de tubería 2 pulgadas & $74^{\circ} 32^{\prime} 24.05^{\prime \prime} \mathrm{O}$ & $4^{\circ} 31^{\prime} 27.70^{\prime \prime} \mathrm{N}$ \\
\hline 5 & Entrada predio Sr Macedonio & $74^{\circ} 32^{\prime} 31.09^{\prime \prime} \mathrm{O}$ & $4^{\circ} 31^{\prime} 27.72^{\prime \prime} \mathrm{N}$ \\
\hline 7 & Medidor del predio & $74^{\circ} 32^{\prime} 31.78^{\prime \prime} \mathrm{O}$ & $4^{\circ} 31^{\prime} 27.47^{\prime \prime} \mathrm{N}$ \\
\hline 9 & Tanque del predio & $74^{\circ} 32^{\prime} 32.39^{\prime \prime} \mathrm{O}$ & $4^{\circ} 31^{\prime} 27.07^{\prime \prime} \mathrm{N}$ \\
\hline 10 & Paso alto tubería & $74^{\circ} 32^{\prime} 33.22^{\prime \prime} \mathrm{O}$ & $4^{\circ} 31^{\prime} 25.56^{\prime \prime} \mathrm{N}$ \\
\hline
\end{tabular}

Fuente: elaboración propia. 
De conformidad con los datos obtenidos, se procede a hacer el trazado del perfil topográfico a través de la implementación del software AutoCAD (figura 7), mediante el cual fue posible obtener la longitud de la tu- bería requerida y sus respectivos accesorios, atendiendo a las diferencias de nivel entre los puntos 8 y 10 de la tabla 7, a partir de la cual fue posible identificar que el tipo de conducción factible es por gravedad.

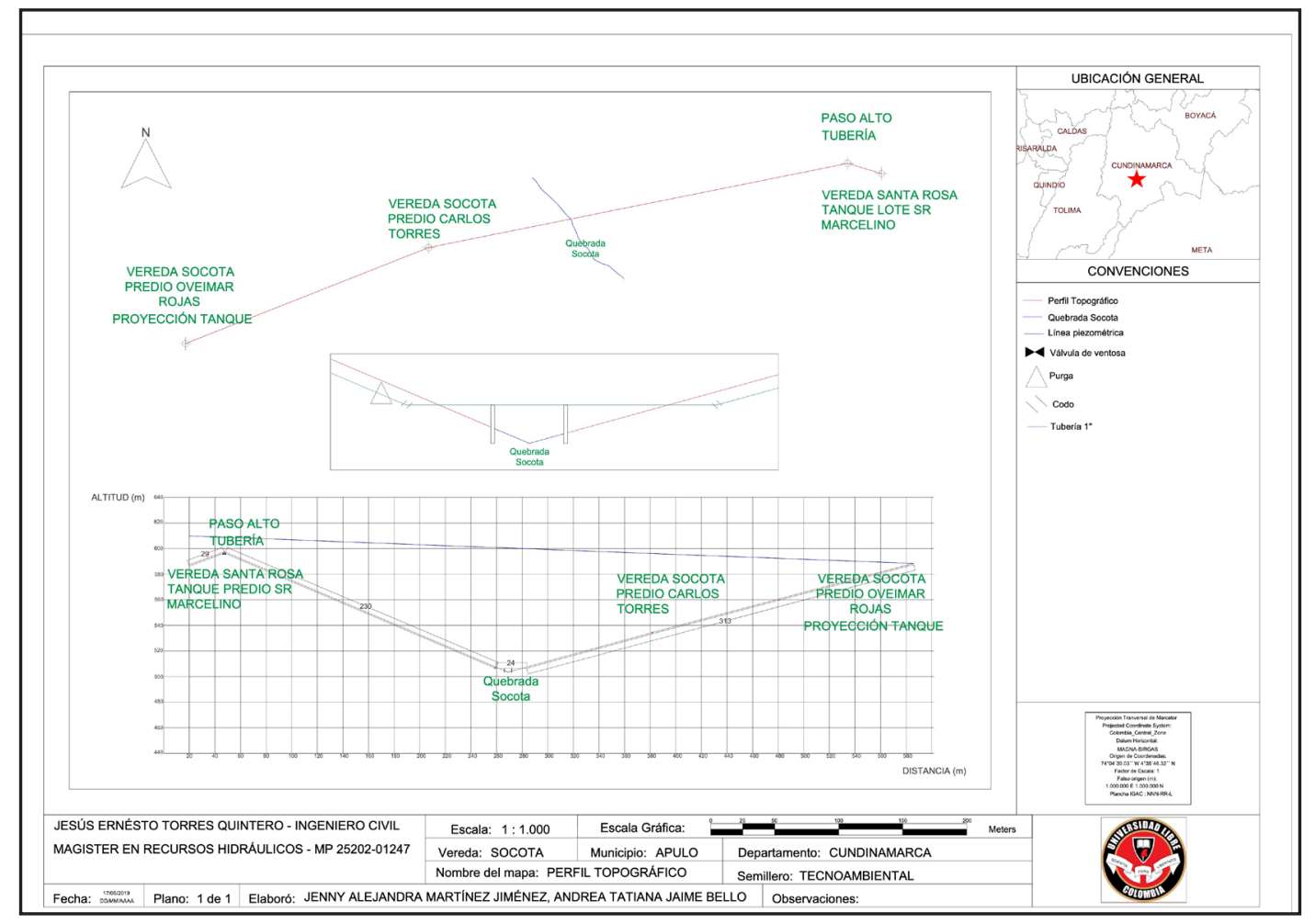

Figura 7. Perfil topográfico

Fuente: elaboración propia.

Finalmente, a partir del perfil topográfico obtenido se realizaron los cálculos para el diámetro de la tubería:

$$
\begin{gathered}
\left.\emptyset=\left(\frac{0.000295}{0,2785 * 150 *\left(\frac{600.528-582.451}{723.95}\right)}\right)^{0.54}\right)^{\frac{1}{2,63}} \\
\emptyset=0.02347 \mathrm{~m}
\end{gathered}
$$

Por lo tanto, se requiere una tubería en PVC con diámetro de 1 pulgada para transportar el agua hasta el tanque proyectado en la vereda Socotá, con un caudal de $0.000295 \mathrm{~m}^{3} / \mathrm{s}$.

De otro lado, teniendo en cuenta que no se dispone de la curva de consumo horario de la población, para determinar el volumen de consumo máximo horario (VCMH) se utiliza el porcentaje empírico establecido por el RAS para poblaciones pequeñas (1/3) en el cálculo del tanque necesario para el almacenamiento del agua de la vereda.

$$
\begin{aligned}
& V=1.2 * \frac{1}{3} * 25,488 \mathrm{~m}^{3} / \text { día } \\
& V=10,195 \mathrm{~m}^{3}=10,195 \mathrm{~L}
\end{aligned}
$$

De acuerdo con lo anterior, el volumen del tanque necesario para el almacenamiento del agua es de 10,195 L.

\section{Presupuesto}

Con los resultados anteriores se determinaron los precios correspondientes para el diseño realizado, los cuales se obtuvieron a partir de lo establecido por el Instituto de Desarrollo Urbano (IDU, 2019) en el componente económico, conforme al análisis de precios unitarios (APU), como se aprecia en la tabla 8. 
Tabla 8. Presupuesto para el desarrollo de la alternativa de abastecimiento de agua potable (pesos colombianos)

\begin{tabular}{ccccc}
\hline \multicolumn{1}{c}{ Inversión } & & \\
\hline Ítems & Unidad & Cantidad & Costo unitario & Costo total \\
\hline Excavación manual & $\mathrm{m}$ & 231,68 & $\$ 26.499$ & $\$ 6.139 .288$ \\
\hline Tubería PVC D=1" RDE 21 & $\mathrm{m}$ & 724,00 & $\$ 12.183$ & $\$ 8.820 .492$ \\
\hline Válvula Ventosa 1" & Unidad & 1,00 & $\$ 392.568$ & $\$ 392.568$ \\
\hline Estructura metálica paso tubería & Unidad & 1,00 & $\$ 7.000 .000$ & $\$ 7.000 .000$ \\
\hline Válvula purga 1" & Unidad & 1,00 & $\$ 299.800$ & $\$ 299.800$ \\
\hline Válvula compuerta & Unidad & 2,00 & $\$ 262.224$ & $\$ 524.448$ \\
\hline Tanque 10,000 L & Unidad & 1,00 & $\$ 5.600 .000$ & $\$ 5.600 .000$ \\
\hline
\end{tabular}

Fuente: elaboración propia con datos del IDU (2019).

Entre los datos del IDU no existe un tanque con capacidad aproximada de 10,195 L. Sin embargo, un valor aproximado para un tanque con las proporciones necesarias que requiere la vereda es de COP 5,712,000, este valor es la sumatoria de un tanque de $10,000 \mathrm{~L}$ (COP $5,600,000)$ y un tanque de $200 \mathrm{~L}$ (COP 112,000).

\section{DISCUSIÓN}

Teniendo en cuenta las condiciones en las que se encontraba la excavación realizada por los habitantes de la vereda, y de conformidad con los resultados de la caracterización del agua subterránea obtenidos, se evidencia que el valor de turbidez no es propia de este tipo de agua, según lo descrito por Custodio (1996, p. 26): “La pequeñez de los canalículos por los que circula el agua hace que el transporte de masa se reduzca a las substancias disueltas y ciertos coloides, y así el agua carece de turbidez". Adicionalmente, este elevado valor puede ser relacionado con lo descrito por $\mathrm{Ca}$ rrasco $(1988$, p. 82$)$ :
La turbidez del agua puede deberse a varias causas: partículas finas de origen mineral, detritus constituidos por material inorgánico u orgánico y microorganismo. Las partículas orgánicas llevan una importante flora bacteriana y micótica en su superficie empleando la partícula como sustrato nutritivo. También las partículas minerales adsorben nutrientes en su superficie, encontrando allí los microorganismos un medio adecuado para su vida. Puede constatarse que cuando un aumento de turbidez lleva parejo un aumento del número de bacterias se debe a materia orgánica en suspensión, si el aumento de turbidez no influye o lo hace de forma escasa sobre el número de bacterias se debe a materia inorgánica.

Sin embargo, se evidencia la existencia de investigaciones en las que se obtienen resultados similares, como la desarrollada por Gómez (2009), en la que se obtiene un valor de turbidez de 24,8 UNT en el aljibe número A25 La Mareiba, con profundidad aproximada de 6 metros bajo tierra. 
En el estudio hidrológico realizado para evaluar las condiciones actuales de la vereda se puede observar que la mayor parte del año cuentan con un déficit de aguas lluvias por bajas precipitaciones. Además, aun cuando es posible establecer dos períodos de precipitaciones que permiten el almacenamiento de agua, se evidencia que se superan los límites de escasez de agua debido a que las precipitaciones de estos períodos no son suficientes para lograr su equilibrio con los valores de evapotranspiración, como especifican Hernández et al. (2014) en un estudio realizado para la zona de los valles interandinos del Tolima, en el cual se manifiesta un comportamiento similar a la vereda Socotá y se expone la importancia de futuros trabajos donde se garantice la disponibilidad de agua.

Los criterios de calidad y continuidad validados para la determinación de la alternativa de abastecimiento de agua potable adecuada para la vereda Socotá se relacionan como criterios clave en la investigación de Lopez-Mandavera (2015), donde son incluidos para la determinación de factores como fiabilidad y responsabilidad, lo cual posibilita la identificación de estos factores como fundamentales en la evaluación de la satisfacción de las necesidades de los usuarios actuales o potenciales del servicio. Esto se refleja también en el análisis realizado por Basallo-Barbosa et al. (2015), en el que se permite la aplicación de la norma Iso 9001 para la valoración de la satisfacción de los usuarios a partir de los criterios previamente mencionados, además de ser asociado de forma paralela a las encuestas realizadas por entidades como las Empresas Públicas del Quindío (2016) y en la evaluación de prestadores realizada por la Superintendencia de Servicios Públicos Domiciliarios (2019).

El desarrollo inclusivo de zonas rurales como la vereda Socotá es un factor que ha venido siendo tratando por el Gobierno de Colombia y que se encuentra contemplado dentro de los ámbitos fundamentales para la Organización para la Cooperación y el Desarrollo Económicos, la cual afirma que "La atención que actualmente se está prestando al desarrollo urbano debe compensarse con un mayor interés en el papel que representan las características y las redes territoriales en un enfoque holístico del desarrollo rural" (OCDE, 2015, p. 17). Sobre el tema, además de la importancia de disminuir las brechas existentes entre las áreas rurales y urbanas del país en temas como el ac- ceso a servicios públicos de calidad, el Banco de Desarrollo de América Latina (2018, p. 1) sostiene que:

[...] acortar las brechas de acceso al agua y saneamiento entre las zonas urbanas y rurales se ha convertido en una de las grandes tareas pendientes de la región, lo cual demanda, con sentido de urgencia, un mayor compromiso por parte de los gobiernos y organismos de cooperación para revertir esta situación de desigualdad.

A partir de esta información, es posible evidenciar la trascendencia del desarrollo de proyectos que incentiven el avance del área rural.

\section{CONCLUSIONES}

Se atiende a la posibilidad de que los altos valores de turbidez obtenidos en la presente investigación sean producto de la contaminación de la muestra debido a la exposición del agua a la caída de material orgánico y a la falta de información sobre las características del acuífero, siendo importante la adquisición de datos sobre atribuciones como el tipo de recarga y las formaciones rocas cercanas al mismo para el desarrollo de estudios posteriores sobre esta alternativa.

El sistema de abastecimiento de agua actualmente empleado en la vereda para la recolección de aguas Iluvias no es suficiente para satisfacer las necesidades básicas de los habitantes en relación con el análisis de la precipitación y la evapotranspiración realizados, por lo tanto, es de vital importancia la implementación de un sistema de abastecimiento que cumpla con las características fundamentales para el consumo humano.

De conformidad con los criterios de viabilidad establecidos para la validación de la mejor alternativa de suministro de agua potable para la vereda Socotá, quedan abiertos canales investigativos asociados a la mejora del sistema de abastecimiento planteado, así como futuras evaluaciones de la efectividad de la alternativa diseñada, teniendo en cuenta que la presente investigación estableció los criterios técnicos base para la ejecución y construcción de la conexión con el acueducto Asuarcopsa.

La investigación realizada pretende incentivar el desarrollo de proyectos eficientes que permitan reducir las brechas existentes entre las zonas rurales y urbanas del país en relación con el acceso a los servicios 
públicos domiciliarios, contribuyendo de esta manera a un avance social y de infraestructura equitativo que permita satisfacer las necesidades de las poblaciones vulnerables.

\section{REFERENCIAS}

Alcaldía Municipal de Apulo (2016). Plan de Desarrollo: Territorio de oportunidades para la inversión, el progreso y el desarrollo social. Alcaldía Municipal de Apulo.

Aliaga, G. (2006). Juan Peña Llopis. Sistemas de Información Geográfica aplicados a la gestión del territorio. Revista de geografía Norte Grande, 36, 97-101. https://doi.org/10.4067/S071834022006000200007

Angarita-Zambrano , G. (2016). Estudio de viabilidad para la construcción del acueducto del puesto fluvial avanzado de infanteria de marina No. 63 ubicado en El Encanto, Amazonas [tesis de maestría, Universidad de Manizales, Colombia]. Repositorio Institucional Universidad de Manizales.

Banco de Desarrollo de América Latina. (2018). La brecha urbano-rural, una tarea pendiente en América Latina. Visiones. https://www.caf.com/ es/conocimiento/visiones/2018/11/la-brechaurbano-rural-una-tarea-pendiente-en-americalatina/

Banco Nacional de Obras y Servicios Públicos S.N.C. [BanObras]. (2010). Guía para el desarrollo de estudios de viablilidad para proyectos del promagua: Proyectos de Agua Potable. Banco Nacional de Obras y Servicios Publicos S.N.C.

Basallo-Barbosa, L. B., Mosquera-Cerquera, G. A., \& Leal-Céspedes, J. C. (2015). La comunicación y satisfacción del cliente externo desde el sistema de gestión de calidad en la empresa de Acueducto y Alcantarillado de Villavicencio, E.S.P. Revista electrónica de la Facultad de Ciencias Económicas de la Universidad de Los Llanos, 2(1), 19-22. https://doi.org/10.22579/23463910.119

Botero-Monsalve , J. P., González-Reyes , G. P., \& Sánchez Ruíz, C. A. (2017). Diagnóstico del estado actual de redes y evaluación técnico-económica de las alternativas para la optimización del sistema de acueducto del municipio de Anapoima [trabajo de grado, Universidad Católica de Colombia]. Repositorio Universidad Católica de Colombia.

Bustamante, A., Pérez , A., Espitia, J., \& Cárdenas , E. (2013). Análisis de datos meteorológicos para identificar y definir el clima en Yopal, Casanare. Revista Medicina Veterinaria, 25, 85-92. https:// doi.org/10.19052/mv.2301

Carrasco, A. (1988). Hidrogeología del campo de Nija y Acuíferos "marginales" (Almería). En Tecnología de la intrusión en Acuíferos Costeros, TIAC. HTTPS:// AGUAS.IGME.ES/IGME/PUBLICA/TIAC.HTM

Carrasco-Mantilla, W. (2016). Estado del arte del agua y saneamiento rural en Colombia. Revista de Ingeniería, 44, 46-53. https://doi.org/10.16924/ riua.v0i44.923

Congreso de la República de Colombia. (1994, julio 11). Ley 142 de 1994. Por la cual se establece el régimen de los servicios públicos domiciliarios y se dictan otras disposiciones. Servicios Públicos Domiciliarios. Diario Oficial n. 41.433.

Congreso de la República de Colombia. (2001, diciembre 21). Ley 715 de 2001. Por la cual se dictan normas orgánicas en materia de recursos y competencias de conformidad con los artículos 151, 288, 356 y 357 (Acto Legislativo 01 de 2001) de la Constitución Política y se dictan otras disposiciones para organizar la prestación de los servicios de educación y salud, entre otros. Diario Oficial $n .044 .654$.

Custodio, E. (1996). Explotación racional de las aguas subterráneas. Acta Geológica Hispánica, 30(1-3), 21-48.

Departamento Nacional de Planeación [DNP]. (2014). CONPES 3810. DNP.

Díaz-Padilla, G., Sánchez-Cohen, I., Quiroz, R., Garatuza-Payan, J., Watts-Thorp, C., \& CruzMedina, I. R. (2008). Interpolación espacial de la precipitación pluvial en la zona Barlovento y Sotavento del Golfo de México. Agricultura Técnica en México, 34(3), 279-287. 
Empresas Públicas del Quindío. (2016). Encuesta de satisfacción del cliente usuario del servicio de acueducto, alcantarillado y gas. Empresas Públicas del Quindío.

Franek, A., Koncagul, E., Connor, E., \& Hunziker, D. (2015). Agua para un mundo sostenible. UNESCO.

García-Bernal, G. (2017). Respuesta Derecho de peticion Virginia Torres y Otros. Número de Radicado 2685. Alcaldía Municipal de Apulo.

Gómez, J. (2009). Geología, geofísica, hidrogeoquímica $e$ isótopos como herramientas para definir un modelo conceptual hidrogeológico caso de aplicación: acuífero costero del municipio de Turbo [tesis de maestría, Universidad Nacional de Colombia]. Repositorio Universidad Nacional de Colombia.

Hernández, A., Mateus , C., \& Orduz, J. (2014). Características climáticas y balance hídrico de la lima ácida Tahití (Citrus Latifolia Tanaka) en cinco productoras de Colombia. Revista Colombiana de Ciencias Hortícolas, 8(2), 217-229. https://doi. org/10.17584/rcch.2014v8i2.3215

Huérfano-Maciado, J. A., \& Segura-Garzón , A. D. (2019). Diagnóstico y optimización del sistema de acueducto veredal ASUARCOPSA de Anapoima entre la bocatoma y la planta de tratamiento [trabajo de grado, Universidad Católica de Colombia]. Repositorio Universidad Católica de Colombia.

Instituto de Desarrollo Urbano [IDU]. (2019). Precios Unitarios de Referencia 2018-II + Mano de Obra 2019. IDU.

Instituto de Hidrología, Meteorología y Estudios Ambientales [IDEAM]. (2015). Estudio Nacional de Agua 2014. IDEAM.

Instituto Geográfico Agustín Codazzi [IGAC]. (2014). Metodología para la clasificación de las tierras por su capacidad de uso. IGAC.

López, R. (2003). Elementos de diseños para acueductos y alcantarillados (segunda edición). Escuela Colombiana de Ingeniería Julio Garavito.
López-Mandavera, C. A. (2015). Medición y control en el servicio al cliente de la empresa de acueducto de Cajicá y como resultado implementar una estrategia para la mejora continua. Universidad Militar Nueva Granada.

Marín, V. (2010). Evaluación de la relación entre la evapotranspiración potencial téorica y la evapotranspiración registrada en los departamentos de Cundinamarca y Valle del Cauca [trabajo de grado, Pontifica Universidad Javeriana]. Repositorio Pontifica Universidad Javeriana.

Martínez-Austria, P. F. (2013). Los retos de la seguridad hídrica. Tecnología y ciencias del agua, 4(5), 165180.

Ministerio de la Protección Social \& Ministerio de Ambiente, Vivienda y Desarrollo Territorial. (2007, 22 de junio). Resolución 2115 de 2007. Por medio de la cual se señalan características, instrumentos básicos y frecuencias del sistema de control y vigilancia para la calidad del agua para consumo humano. Ministerio de la Protección Social \& Ministerio de Ambiente, Vivienda y Desarrollo Territorial.

Ministerio de Vivienda, Ciudad y Territorio. (2017, 8 de juni甲 ds] Resolución 0330 de 2017. Reglamento Técnico del Sector de Agua Potable y Saneamiento BásidęcMin)isterio de Vivienda, Ciudad y Territorio.

Montaner, M., \& Almohalla, E. (1988). Aproximación por el método de Thornthwaite al cálculo de infiltración de lluvia útil. Papeles de Geografía, 14, 223-235.

Organización para la Cooperación y el Desarrollo Económicos [OCDE]. (2015). Colombia. Políticas prioritarias para un desarrollo inclusivo. Mejores políticas. OCDE.

Peña, H. (2016). Desafíos de la seguridad hídrica en América Latina y El Caribe. Recursos Naturales $e$ Infraestructura, 178, 7-8.

Pérez-Moreno, F., Prieto-García, F., Rojas-Hernández, A., Galán-Vidal, C. A., Marmolejo-Santillán, Y., Romo-Gómez, C., Castañeda-Ovando, A., Rodríguez-Ávila, J. A., \& Barrado-Esteban, E. (2003). 
Caracterización química de aguas subterráneas en pozos y un distribuidor de agua de Zimapán, Estado de Hidalgo, México. Hidrobiológica, 13(2), 95-102.

Quereda, J. (2005). Curso de climatología general. El balance hídrico: la evapotranspiración. Universidad Jaume I.

Sistema de Información de Agua Potable y Saneamiento Básico [SIASAR]. (s.f). Reporte de respador de servicio. Asociación de usuarios del acueducto regional de Anapoima ASUARCOPS. SIASAR.

Superintendencia de Servicios Públicos Domiciliarios. (2019). Evaluacion integral de prestadores Aguas del Tequendama S.A. E.S.P. Superintendencia de Servicios Públicos Domiciliarios. 